\title{
Associations between adiposity and physical activity and sedentary behaviour patterns in older women
}

\author{
Zuzana Svozilová1,*, Jana Pelclová1, Jana Pechová1, Miroslava Přidalová1, Izabela Zając-Gawlak², \\ Lenka Tlučáková ${ }^{3}$, and Tereza Kaplanová ${ }^{1}$ \\ ${ }^{1}$ Faculty of Physical Culture, Palacký University Olomouc, Olomouc, Czech Republic; ${ }^{2}$ The Jerzy Kukuczka Academy \\ of Physical Education, Katowice, Poland; and ${ }^{3}$ Faculty of Sports, University of Prešov, Prešov, Slovakia
}

Copyright: () 2019 Z. Svozilová et al. This is an open access article licensed under the Creative Commons Attribution License (https://creativecommons.org/licenses/by/4.0/).

\begin{abstract}
Background: Despite broad interest in physical activity (PA) and excessive sitting, it remains unclear what the actual patterns of PA and sedentary behaviour (SB) in older adults are and how they are associated with adiposity. Objective: The aim of this study was to investigate the cross-sectional associations between the total amount and defined bouts of PA and SB with adiposity indicators in older women. Methods: Data on 313 community-dwelling women was used. All women wore an accelerometer for one week and undergone the body composition analysis. We used three adiposity indicators: fat mass percentage (FM\%), visceral fat area (VFA), fat mass index (FMI); and the fatfree mass index indicator (FFMI). In multiple linear regression analyses, we adjusted the models for the following confounders: age, wear time, socio-demographic information, smoking, and health status. Results: The mean values of FM\%, VFA, FMI, and FFMI were $36.1 \%, 125.9 \mathrm{~cm}, 10 \mathrm{~kg} \cdot \mathrm{m}^{-2}$ and $17 \mathrm{~kg} \cdot \mathrm{m}^{-2}$, respectively. Each additional 150 minutes of MVPA per week (regardless of bout length) was associated with a decrease of $3.0 \%$ in $\mathrm{FM} \%, 12 \mathrm{~cm}^{2}$ in VFA, and $1.5 \mathrm{~kg} \cdot \mathrm{m}^{-2}$ in FMI. Regarding strong association with bout frequency, doing MVPA lasting $\geq 10$ minutes 15 times/week (to meet the target of at least 150 minutes of MVPA/week) would be associated with a decrease of $4.8 \%$ in FM\%, $24.15 \mathrm{~cm}^{2}$ in VFA, and $2.55 \mathrm{~kg} \cdot \mathrm{m}^{-2}$ in FMI. Significant positive associations for FM\%, VFA, and FMI were found with the duration and frequency of sedentary bouts lasting $\geq 20$ minutes ( $\beta$ ranging from 0.05-0.42). Conclusions: Significant associations between fat indicators and both PA and SB were found in elderly women. The beneficial associations were much larger for frequency than for duration of bouted MVPA lasting $\geq 10$ minutes. The results from this study using SB and PA in terms of total accumulated time and different bouts could be useful for designing interventions for community-dwelling older women.
\end{abstract}

Keywords: accelerometer, bouts, fat mass, visceral fat, moderate-to-vigorous physical activity

\section{Introduction}

The prevalence of adiposity in developed countries is growing across the age spectrum (Doak, Wijnhoven, Schokker, Visscher, \& Seidell, 2012; Gába \& Přidalová, 2014; World Health Organization, 2016). Especially older women are at high risk of abdominal obesity after the menopausal transition years (Loveloj, Champagne, de Jonge, Xie, \& Smith, 2008). With regard to the health consequences of adiposity (Gardiner et al., 2011; Penedo, Schneiderman, Dahn, \& Gonzalez,

\footnotetext{
* Address for correspondence: Zuzana Svozilová, Institute of Active Lifestyle, Faculty of Physical Culture, Palacký University Olomouc, třída Míru 117, 71111 Olomouc, Czech Republic. E-mail: zuzana.svozilova@upol.cz
}

2004), older adults are the group that is most sensitive to comorbidities, because they also form the least active group in society (Harvey, Chastin, \& Skelton, 2015). Moreover, excessive sitting is recognised as a risk factor for non-communicable diseases and all-cause mortality among older adults (Harvey, Chastin, \& Skelton, 2013).

It has been established that sitting time is positively associated with adiposity in older adults (Bankoski et al., 2011; Gennuso, Gangnon, Matthews, ThraenBorowski, \& Colbert, 2013; Gianoudis, Bailey, \& Daly, 2015; Inoue et al., 2012) and physical activity (PA) might be a solution that could help to prevent and treat adiposity in this population (Hill \& Wyatt, 2005; Owen, Bauman, \& Brown, 2009; Recio-Rodríguez et al., 2017). And, more generally, PA is associated with many health benefits and is a relevant factor 
influencing independence and healthy aging (World Health Organization, 2017). The current PA recommendations indicate that older adults should get at least 150 minutes of moderate-intensity aerobic PA throughout the week on the condition that all activities should be performed for at least 10 minutes (World Health Organization, 2010). However, most of seniors' PA comprises light-intensity PA, whereas the most intense type, vigorous PA, is hardly achievable in older adults (UK Department of Health, 2011). On the other hand, the recommendations relating to older adults' sedentary behaviour (SB) do not provide clear guidance, only suggesting minimising the amount of time spent being sedentary for extended periods and breaking up long periods of sitting as often as possible (Australian Government, Department of Health, 2014). For this reason, a detailed investigation of patterns of daily PA and SB, including bouts of different durations and their frequency (reflecting sedentary breaks), is necessary to gain an understanding of the associations with adiposity. This is possible mainly thanks to instruments for the objective monitoring of PA and SB. In geriatric research, the use of accelerometers has been established as a reliable and valid tool for the assessment of PA (Foong et al., 2014; Harris et al., 2009). Especially in older adults, the association between adiposity markers and PA might be highly influenced by the assessment tool. The association might be stronger when PA is assessed by means of accelerometry, compared with questionnaires (Sabia et al., 2015) or only objective but not self-reported PA is associated with adiposity (Recio-Rodríguez et al., 2017).

There are different findings from previous studies which investigated specific bouts of PA. Some studies found stronger associations between minutes of moderate-to-vigorous PA (MVPA) accumulated in bouts lasting $\leq 10$ minutes and adiposity parameters than the same accumulated in bouts lasting $>10$ minutes (Loprinzi, Crush, \& Joyner, 2017; Strath, Holleman, Ronis, Swartz, \& Richardson, 2008). A study of older British men suggested similar effects for adiposity regardless of meeting the requirement for 10-minute bouts of MVPA (Jefferis et al., 2016). Regarding SB, a large proportion of sedentary time appears to be accrued in short bouts ( $<10$ minutes; Yerrakalva et al., 2017), and short bouts of 1-15 minutes were found to be associated with lower adiposity in older adults (Jefferis et al., 2016).

Recently, there have been many investigations of SB and PA in association with geriatric-relevant health outcomes (de Rezende, Rey-López, \& Matsudo, 2014; Taylor et al., 2004). However, these studies have primarily used subjective assessment methods. Moreover, only a few studies (Chastin, Ferriolli, Stephens, Fearon, \& Greig, 2011; Ko, Stenholm, \& Ferrucci,
2010) investigated specific patterns of both PA and SB in an older adult population in relation to objectively measured adiposity parameters. In this study, we have examined all levels of PA, including SB, using accelerometers. Furthermore, we have used objective measurement of body composition (BC) to assess diverse adiposity indicators. This study aims to investigate the cross-sectional associations between the total amount and defined bouts of PA and SB and adiposity indicators in older women.

\section{Methods}

\section{Subjects and design}

Four hundred and eight healthy community-dwelling women (aged 55-83) from Czech Republic, Slovakia and Poland were recruited throughout 2009 and 2018 to participate in the assessment of PA, SB, and BC. The participants were approached during personal visits on University of the Third Age classes and selected local senior clubs. The exclusion criteria for the study were major knee or hip surgery in the previous twelve months or a physical handicap that might have interfered with the $\mathrm{BC}$ and $\mathrm{PA}$ measurement (e.g., motor skills disorder, amputation, or paralysis). Out of 408 participating women, 71 had to be excluded due to missing valid accelerometer data. Moreover, 24 women without self-reported socio-demographic information were also excluded from the analyses. Finally, data of 313 were analysed (217 from the University of the Third Age and 96 from local senior clubs).

The Institutional Ethics Committee of the Faculty of Physical Culture of Palacký University Olomouc provided ethical approval (No. 20/2016). All participants provided written informed consent, which was conducted in accordance with the Helsinki Declaration.

\section{Body composition and anthropometric measurement}

The standing height was measured to the nearest 0.1 $\mathrm{cm}$ using a P-375 portable anthropometer (Trystom, Olomouc, Czech Republic), while the women were barefoot. BC, including weight (to the nearest $0.1 \mathrm{~kg}$ ), was assessed by means of multi-frequency bioelectrical impedance analysis using the InBody 720 device (Biospace Co., Seoul, Korea) with the manufacturer's equation. All the women were required fast for at least 4 hours, hydrate properly for 24 hours preceding the measurement. The following indicators were assessed: fat mass percentage (FM\%), visceral fat area (VFA), fat mass index (FMI), and fat-free mass index (FFMI). FFMI does not belong to adiposity indicators, since consists of muscles, connective tissues, dense connective tissues and internal organs. However, it was added 
to all analyses to obtain a more comprehensive view of body composition issue. The FFMI $\left(\mathrm{kg} \cdot \mathrm{m}^{-2}\right)$ and body FMI $\left(\mathrm{kg} \cdot \mathrm{m}^{-2}\right)$ were derived as body fat-free mass $(\mathrm{kg})$ and body fat mass $(\mathrm{kg})$, respectively, divided by body height squared $\left(\mathrm{m}^{2}\right)$. Body mass index (BMI) was calculated by dividing body weight $(\mathrm{kg})$ by the square of body height $\left(\mathrm{m}^{2}\right)$. VFA was defined as a cross sectional area of visceral fat in the abdomen at the umbilical level $\left(\mathrm{L}_{4}-\mathrm{L}_{5}\right)$. The values can be estimated using multifrequency bioimpedance analysis with the InBody 720 or by computed tomography which is considered a less convenient than bioimpedance method (Park et al., 2016). The cut-off point $100 \mathrm{~cm}^{2}$ of visceral fat accumulation was determined as the emergence of many adverse health problems (Piché et al., 2008).

\section{Sedentary behaviour and physical activity assessment}

SB and PA were assessed using ActiGraph GT1M accelerometers (ActiGraph, Pensacola, FL, USA). All the participants wore the device during waking hours for at least eight consecutive days, except for bathing, swimming, and sleeping. The time sampling interval was set at 60 -second epochs. In this study, the accelerometer output in counts per minute (cpm) was derived using adult population cut-offs, based on previous evidence that the attendees of the University of the Third Age and senior clubs are considered more physically active (Pelclová, Gába, Tlučáková, \& Pośpiech, 2012; Zając-Gawlak et al., 2016). Intensities of $\leq 99 \mathrm{cpm}$, 100-1951 cpm, and $\geq 1952 \mathrm{cpm}$ correspond with SB, light-intensity PA (LIPA), and MVPA, respectively (Freedson, Melanson, \& Sirard, 1998). The summary of the time spent in the defined thresholds was calculated as total sedentary time and total time spent in LIPA and MVPA. Non-wear time was defined as $\geq 60$ consecutive minutes of zero activity counts, allowing interruptions of counts above 0 for two minutes. Additionally, the duration (time spent on bouts of a defined length) and frequency (number of bouts) per day (reflecting sedentary breaks) of particular activity bouts were considered. A bout was determined as a period spent in a defined intensity. When the accelerometer cpm raising over the particular threshold, that specific bout was instantly terminated. We examined the frequency and duration of sedentary bouts with a length of $\geq 10, \geq 20$, and $\geq 30$ minutes with all consecutive minutes of $\leq 99 \mathrm{cpm}$. Each minute in which the device registered $\geq 100 \mathrm{cpm}$ was considered as a sedentary break. Further, a 10-minute MVPA bout was defined as 10 or more consecutive minutes above the MVPA activity count threshold following MVPA recommendations (World Health Organization, 2016).

\section{Covariates}

Demographic factors (age, employment status), socioeconomic (education), health (self-reported health), behavioural (light-intensity PA, MVPA, and smoking status), and environmental factors (living in an apartment) were obtained through a questionnaire and were included in the analysis as covariates. Self-reported health was assessed using simple question, which asks about the current health of the respondents, and the responds were classified as "excellent", "very good", "good", "fair" or "poor". These confounders have been identified as strong predictors of SB (Chastin et al., 2015) or have been found to be associated with PA or SB in older Central European adults (Pelclová et al., 2009). Furthermore, the accelerometer wear time was calculated and used to control the analysis.

\section{Data analysis}

The women provided valid accelerometer data and personal information, which were used as covariates in all the analyses. Accelerometer data was considered valid if the wear time was at least 10 hours a day on a minimum of three weekdays and one weekend day (Hart, Swartz, Cashin, \& Strath, 2011). The accelerometer data was processed using ActiLife (Version 6.13.3; ActiGraph, Pensacola, FL, USA). All analyses were performed using the SPSS software (Version 22 for Windows; SPSS, Chicago, IL, USA). Descriptive statistics are presented as means, standard deviations, and 95\% confidence intervals unless stated otherwise. Normal data distribution was found in all PA and adiposity variables. Statistical significance was set at $p<.05$.

To explain the observed data, analysis of variance was used to analyse the differences in adiposity parameters among the MVPA and SB quartiles. The cut-off points of the quartiles were 20,34.9, and 49.4 minutes/day for MVPA and 404, 474.3, and 523.7 minutes/day for SB. To confirm the linear trend, a test for linearity was used.

In multiple linear regression analyses, we analysed the associations of total SB, LIPA and MVPA and the frequency and duration of SB and MVPA bouts with adiposity indicators. All the analyses were adjusted for confounding variables. The adiposity indicators were used as dependent (outcome) variables. In the first analysis, the total sedentary time and frequency and duration of defined sedentary bouts were used as the exposure. The analysis was adjusted for age, wear time, and additional confounders. To find out if PA influences SB, the model was also adjusted for MVPA. LIPA was not included in the analysis as a confounder for reasons of collinearity. The correlation coefficient between LIPA and sedentary time was lower than -.7. In the second analysis, the total time occupied by LIPA was used as the exposure, with adjustment for the 
same variables except MVPA. The third time, the total time spent on MVPA and the frequency and duration of 10-minute MVPA bouts were used as the exposure. Equally, the regression model was created with the MVPA confounder being replaced by the total time spent on SB.

\section{Results}

Baseline descriptive characteristics of the 313 older community-dwelling women (55-83 years old) included in this study are presented in Table 1 . On average they spent 466.8 minutes daily on SB, 324.8 minutes on LIPA, and 38.44 minutes on MVPA. One hundred thirty-three of the women were classified as obese $(42 \%)$ and 71 of the women as overweight (23\%). The wear time of the accelerometers was, on average, 13.9 hours per day and the participants had seven valid days on average. The mean values of $\mathrm{FM} \%$, VFA, FMI, and FFMI were $36.1 \%$, $125.9 \mathrm{~cm}^{2}, 10 \mathrm{~kg} \cdot \mathrm{m}^{-2}$, and $17 \mathrm{~kg} \cdot \mathrm{m}^{-2}$, respectively.

Significant differences in FM\%, FMI and VFA (Figure 1) were found between the MVPA and SB quartiles $(p<.01)$, i.e. the women with a higher amount (the fourth quartile) of MVPA and a lower amount of SB had lower values of both fat parameters. Moreover, a linear trend was confirmed for these variables $\left(p_{\text {trend }}=.01\right)$. A linear trend was also confirmed in the FFMI indicator, but only in MVPA, not in SB.

Table 2 shows the analyses where the associations of PA and SB (independent) variables with adiposity indicators and FFMI were investigated. The beta coefficient $(\beta)$ represents the result of each analysis adjusted for age, wear time, total MVPA (or total SB in analysis with the PA level modelled as an independent variable), and socio-demographic and health confounders (education, housing, location, health status, smoking status, and employment).

Table 1

Descriptive characteristics of sample $(N=313)$

\begin{tabular}{lrc}
\hline & Mean & $95 \% \mathrm{CI}$ \\
\hline Age and somatic characteristics & & \\
Age (years) & 66.6 & {$[65.8,67.3]$} \\
Body height $(\mathrm{cm})$ & 160.9 & {$[160.3,161.7]$} \\
Body weight $(\mathrm{kg})$ & 70.2 & {$[68.9,71.5]$} \\
Body mass index $\left(\mathrm{kg} \cdot \mathrm{m}^{-2}\right)$ & 27.1 & {$[26.6,27.6]$} \\
Fat mass percentage $(\%)$ & 36.1 & {$[35.3,36.9]$} \\
Visceral fat area $\left(\mathrm{cm}^{2}\right)$ & 125.9 & {$[122.1,129.8]$} \\
Fat mass index $\left(\mathrm{kg} \cdot \mathrm{m}^{-2}\right)$ & 10.0 & {$[9.7,10.4]$} \\
Fat-free mass index $\left(\mathrm{kg} \cdot \mathrm{m}^{-2}\right)$ & 17.0 & {$[16.9,17.2]$} \\
Physical activity & & \\
LIPA (minutes/day) & 324.8 & {$[316.0,335.8]$} \\
Moderate physical activity (minutes/day) & 38.3 & {$[35.7,40.9]$} \\
MVPA (minutes/day) & 38.8 & {$[36.1,41.5]$} \\
Average length of MVPA bout (minutes/day) & 13.9 & {$[13.1,14.6]$} \\
Duration of MVPA bouts $\geq 10$ minutes (minutes/day) & 18.9 & {$[16.9,21.0]$} \\
Frequency of MVPA bouts $\geq 10$ minutes (times/day) & 1.1 & {$[1.0,1.2]$} \\
Monitor wear time (hours/day) & 13.9 & {$[13.7,14.0]$} \\
Sedentary behavior & & \\
Sedentary time (minutes/day) & 466.8 & {$[456.6,476.9]$} \\
Average length of sedentary bout (minutes/day) & 5.7 & {$[5.6,5.9]$} \\
Duration of sedentary bouts $\geq 10$ minutes (minutes/day) & 277.3 & {$[267.1,287.8]$} \\
Duration of sedentary bouts $\geq 20$ minutes (minutes/day) & 177.0 & {$[167.7,186.0]$} \\
Duration of sedentary bouts $\geq 30$ minutes (minutes/day) & 118.7 & {$[110.9,126.5]$} \\
Frequency of sedentary bouts $\geq 10$ minutes (times/day) & 12.5 & {$[12.1,12.8]$} \\
Frequency of sedentary bouts $\geq 20$ minutes (times/day) & 5.0 & {$[4.8,5.2]$} \\
Frequency of sedentary bouts $\geq 30$ minutes (times/day) & 2.5 & {$[2.4,2.7]$} \\
\hline
\end{tabular}

Note. $\quad \mathrm{CI}=$ confidence interval; $\mathrm{LIPA}=$ light-intensity physical activity; $\mathrm{MVPA}=$ moderate-to-vigorous physical activity. 

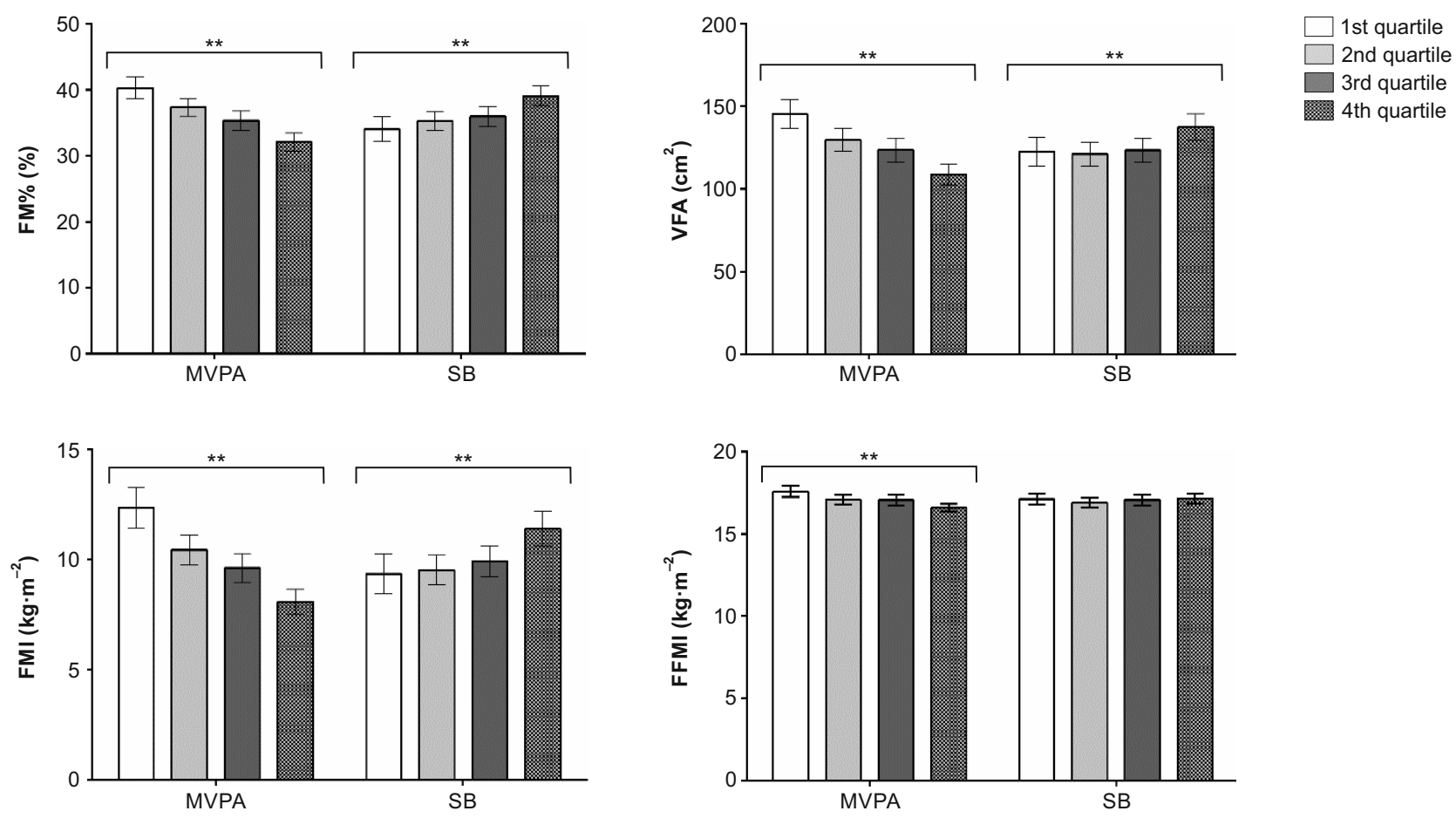

Figure 1. Differences in adiposity indicators and FFMI between differentially active and sedentary women. FM $\%=$ fat mass percentage; VFA = visceral fat area; FMI = fat mass index; FFMI = fat-free mass index; MVPA = moderate-tovigorous physical activity; $\mathrm{SB}=$ sedentary behaviour. $\quad * * p<.01$.

\section{Association between PA patterns and adiposity}

LIPA was inversely associated with FM\%, VFA, and FMI, but the regression coefficients were small and only significant in FM\%. All the characteristics of MVPA were highly significantly associated with all the adiposity indicators $(p<.01)$. The $\beta$ coefficients of the total time spent on MVPA in comparison to time spent on activities with bouts $\geq 10$ minutes were very similar. Coefficients are expressed per minute a week of MVPA. Thus, multiplying by 150 (the weekly recommendation for healthy older adults), each additional 150 minutes of MVPA per week (regardless of whether it was accumulated in bouts lasting $\geq 10$ minutes) was associated with a decrease in all the fat indicators: $3.00 \%(95 \% \mathrm{CI}$ $[-3.00,-1.50])$ lower FM\%, $12 \mathrm{~cm}^{2}$ (95\% CI [-16.50, -7.50]) lower VFA, and $1.5 \mathrm{~kg} \cdot \mathrm{m}^{-2}(95 \% \mathrm{CI}[-1.95$, 1.05]) lower FMI. Very strong associations of fat indicators were found with the frequency of MVPA bouts lasting $\geq 10$ minutes. Coefficients for MVPA bouts lasting $\geq 10$ minutes are expressed per times a week. Meeting a target of MVPA lasting $\geq 10$ minutes 15 times a week (to achieve at least 150 minutes of MVPA a week) would be associated with a decrease in all fat indicators: 4.8\% (95\% CI [-6.45, -3.00]) lower FM\%, $24.15 \mathrm{~cm}^{2}(95 \%$ CI $[-32.7,-15.6])$ lower VFA, and $2.55 \mathrm{~kg} \cdot \mathrm{m}^{-2}(95 \% \mathrm{CI}[-3.45,1.80])$ lower FMI.

\section{Association between SB patterns and adiposity}

Total sitting time and specific patterns of SB expressed as hours and times of bouts lasting $\geq 10, \geq 20$, and $\geq 30$ minutes per week were positively associated with all adiposity indicators. Significant positive associations for all fat (FM\%, VFA, and FMI) indicators were found with the duration and frequency of sedentary bouts lasting $\geq 20$ minutes. Multiplying by 10, an additional 10 hours per week spent on bouts lasting $\geq 20$ minutes was associated with $1.1 \%$ (95\% CI [0.3, 1.9]) higher FM\%, $4 \mathrm{~cm}^{2}$ (95\% CI [0.1, 8.0]) higher VFA, and $0.43 \mathrm{~kg} \cdot \mathrm{m}^{-2}(95 \%$ CI $[0.08,0.78])$ higher FMI. There was no significant association in sedentary bouts lasting $\geq 30$ minutes with adiposity indicators, except for the frequency of bouts lasting $\geq 30$ minutes, where a significant positive association with FM\% was found ( $\beta=0.09, p=.04)$. Significant positive associations for the duration and frequency of bouts lasting $\geq 10$ minutes were found only for FM\% and FMI, but not for VFA. There was a significant association between sedentary bout characteristics and the FFMI indicator.

\section{Discussion}

In this study, we have examined PA, SB, and adiposity in older women. On average, the women were sitting for 


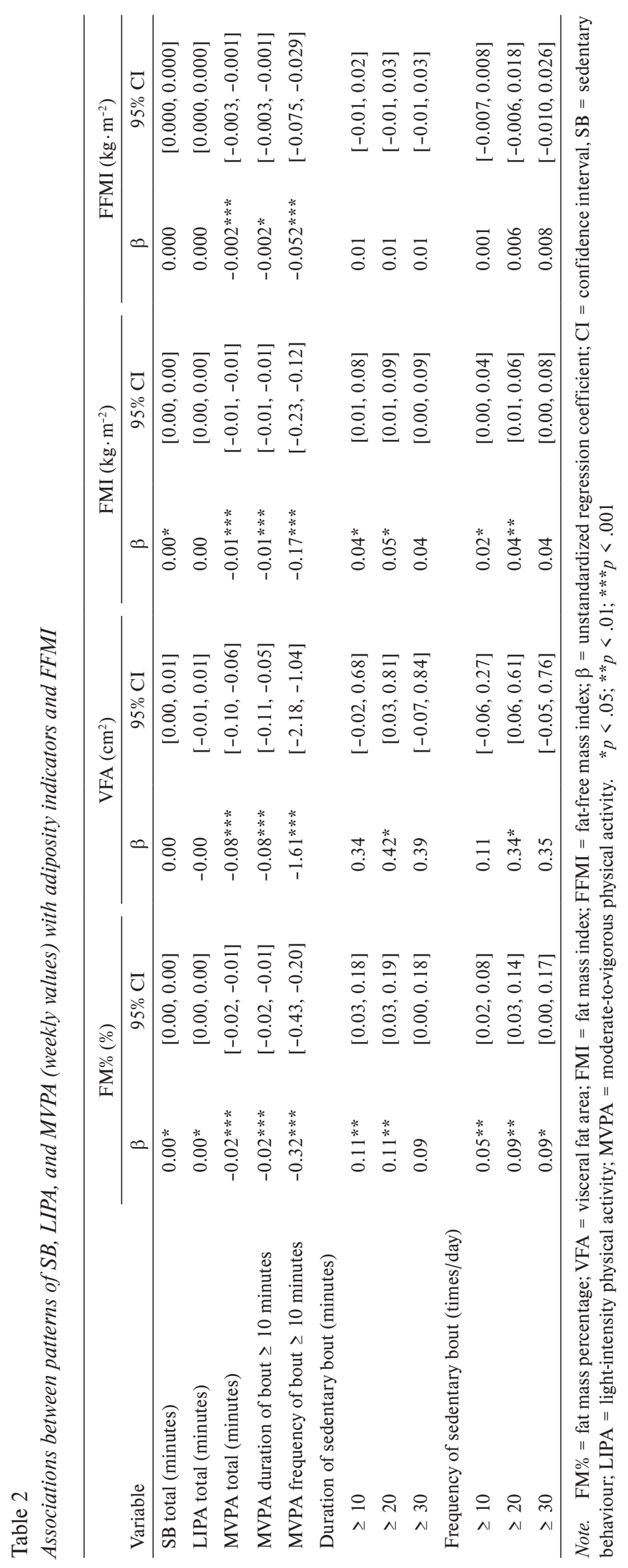


467 minutes/day (7.8 hours), which means than more than $50 \%$ of their waking time was spent sedentarily. This result follows the previous studies in adults aged $60+$ with time spent sedentarily ranging from 5.3-9.4 hours per waking day (Harvey et al., 2015). Looking at patterns of SB, $75 \%$ of the total sitting time was accumulated in bouts lasting $<30$ minutes, confirming the suggestion of previous studies that most sedentary time occurs in bouts of shorter duration in both men (Jefferis et al., 2016) and women (Shiroma et al., 2013). Although the women were physically active compared to others of the same age (even with the employment of MVPA cut-off points for adults), their mean \%FM was $36.1 \%$ and the mean value of BMI $27.1\left(\mathrm{~kg} \cdot \mathrm{m}^{-2}\right)$ suggested overweight or even obesity (Gába et al., 2009; Gába \& Přidalová, 2016; Pelclova, Fromel, Gaba, \& Mitas, 2012). BMI and FM\% values are in line with a study of Czech women (Gába \& Přidalová, 2014).

This cross-sectional study aimed to investigate the associations between the total amount and defined bouts of PA and SB and adiposity indicators in older women. Our findings support previous evidence that higher levels of MVPA (after adjusting for SB) are associated with better health in terms of adiposity (FM\%, VFA, FMI) (Henson et al., 2013; Jefferis et al., 2016). Some studies in large adult samples suggested that bouts of MVPA lasting $\geq 10$ minutes had a significantly stronger association with lower BMI and waist circumference than non-bouted MVPA (Loprinzi et al., 2017; Strath et al., 2008). Our findings in our sample of older women are similar to the study of older British men (Jefferis et al., 2016) in that almost equal beneficial associations with fat indicators were found for total MVPA and MVPA done in bouts lasting $\geq 10$ minutes. To our knowledge, no previous studies investigated both the duration and also the frequency of bouted MVPA lasting $\geq 10$ minutes. In this study, the associations were stronger for the frequency of bouts of MVPA lasting $\geq 10$ minutes (times a week) than for time spent on MVPA lasting $\geq 10$ minutes (minutes a week). In other words, and with respect to the $150 \mathrm{~min}$ utes/week MVPA recommendation, the coefficients for the beneficial associations of meeting the requirement for MVPA lasting $\geq 10$ minutes 15 times per week with each outcome were much larger than the coefficients for 150 minutes/week of MVPA lasting $\geq 10$ minutes.

In our findings, there was significant association between LIPA and FM\%. This association was in the same direction as for MVPA, but the regression coefficient was smaller. Previous research in older adults suggested that almost $90 \%$ of LIPA is accumulated in bouts lasting < 10 minutes (Jefferis et al., 2016); more frequent bouts of LIPA were associated with lower adiposity (BMI, waist circumference, FMI) and insulin levels.

Our findings also correspond with those of previously conducted studies (Bankoski et al., 2011; Gennuso et al., 2013; Gianoudis et al., 2015; Inoue et al., 2012), that lower levels of SB are associated with better health in terms of adiposity. Considering previous studies in older adults (Jefferis et al., 2016; Yerrakalva et al., 2017), we expected more sedentary individuals and those interrupting their sedentary time less often to have a higher positive association with fat indicators. Our study revealed that especially bouts of a particular duration are positively associated with particular fat indicators. While significant positive associations for fat indicators were found with the duration and frequency of sedentary bouts lasting $\geq 10$ minutes and $\geq 20$ minutes, there was almost no significant association between sedentary bouts lasting $\geq 30$ minutes. This might be related to the fact that a high volume of sedentary time is accumulated in shorter bouts in older adults, although any longer bout would be a significant proportion of their total sitting time. Reducing both the duration and frequency of sedentary bouts lasting $\geq 20$ minutes may help to target weight reduction interventions in community-dwelling older women.

\section{Strengths and limitations}

This study benefits from employing objective methods of PA and SB monitoring using accelerometry, although a diversity of studies using different cut-off points for counts and identification of non-wear time might reduce the comparability of accelerometer-based studies in an older adult population. The strength of this study was the identification of patterns of SB and MVPA, using the values of the frequency and duration of bouts. Nevertheless, only bouts of MVPA and SB were taken into consideration, while LIPA was investigated as total time. On the other hand, previous research in older adults suggested that almost $90 \%$ of LIPA is accumulated in bouts lasting $<10$ minutes (Jefferis et al., 2016).

The general limitation of this study is its crosssectional design, as we do not know the effect on the changes of the results from the long-term viewpoint. Moreover, our sample consisted of women who participated in the University of the Third Age or senior clubs, so they were predicted to be more active than other older woman who did not and thus the generalizability of the results might be limited. Moreover, the very narrow age distribution of the group (95\% CI [65.8-67.3]) should be also mentioned as one of the limitations of the study. Although it increases the internal validity of the study, again, the generalizability of the study results is limited. 


\section{Conclusion}

Significant associations between adiposity indicators and both PA and SB were found in the sample of older women. The beneficial associations were much larger for the frequency than for the duration of bouted MVPA lasting $\geq 10$ minutes, suggesting that accumulating MVPA in more bouts lasting $\geq 10$ minutes might have a greater effect on fat-related health consequences than accumulating the same volume of MVPA in fewer but longer bouts.

The results from this study using SB and PA in total accumulated time and different bouts could be useful for designing interventions for community-dwelling older women.

\section{Acknowledgment}

We thank all the volunteers and the entire research team who participated in this study. The study was supported by a research grant from the Czech Science Foundation No. 18-16423S, and by the internal Palacký University Olomouc grant IGA_FTK_2018_003.

\section{Conflict of interest}

There were no conflicts of interest.

\section{References}

Australian Government, Department of Health. (2014). Australia's physical activity and sedentary behaviour guidelines. Retrieved from http://www.health.gov.au/internet/main/ publishing.nsf/Content/3E1E612D573C2B7CCA257C7 500202177/\$File/Tips\&Ideas-Adults-18-64years.PDF

Bankoski, A., Harris, T. B., McClain, J. J., Brychta, R. J., Caserotti, P., Chen, K. Y., ... Koster, A. (2011). Sedentary activity associated with metabolic syndrome independent of physical activity. Diabetes Care, 34, 497-503.

Chastin, S. F. M., Buck, C., Freiberger, E., Murphy, M., Brug, J., Cardon, G., ... Oppert, J. M. (2015). Systematic literature review of determinants of sedentary behaviour in older adults: A DEDIPAC study. International Journal of Behavioral Nutrition and Physical Activity, 12, 1-12.

Chastin, S. F. M., Ferriolli, E., Stephens, N. A., Fearon, K. C. H., \& Greig, C. (2011). Factors that differentiate level of ambulation in hospitalised older adults. Age and Ageing, 41, 111-114.

de Rezende, L. F. M., Rey-López, J. P., \& Matsudo, V. K. R. (2014). Sedentary behavior and health outcomes among older adults: A systematic review. BMC Public Health, 14, 333.

Doak, C. M., Wijnhoven, T. M. A., Schokker, D. F., Visscher, T. L. S., \& Seidell, J. C. (2012). Age standardization in mapping adult overweight and obesity trends in the WHO European Region. Obesity Reviews, 13, 174-191.

Foong, Y. C., Aitken, D., Winzenberg, T., Otahal, P., Scott, D., \& Jones, G. (2014). The association between physical activity and reduced body fat lessens with age - results from a cross-sectional study in community-dwelling older adults. Experimental Gerontology, 55, 107-112.

Freedson, P. S., Melanson, E., \& Sirard, J. (1998). Calibration of the Computer Science and Applications, Inc. accelerometer. Medicine \& Science in Sports \& Exercise, 30, 777-781.

Gába, A., Pelclová, J., Přidalová, M., Riegerová, J., Dostálová, I., \& Engelová, L. (2009). The evaluation of body composition in relation to physical activity in 56-73 year old women: A pilot study. Acta Universitatis Palackianae Olomucensis. Gymnica, 39(3), 21-30.

Gába, A., \& Přidalová, M. (2014). Age-related changes in body composition in a sample of Czech women aged 18 to 89 years: A cross-sectional study. European Journal of Nutrition, 53, 167-176.

Gába, A., \& Přidalová, M. (2016). Diagnostic performance of body mass index to identify adiposity in women. European Journal of Clinical Nutrition, 70, 898-903.

Gardiner, P. A., Healy, Ã. G. N., Eakin, Ã. E. G., Clark, B. K., Dunstan, Ã. D. W., Zimmet, P. Z., \& Owen, N. (2011). Associations between television viewing time and overall sitting: The Australian Diabetes Obesity and Lifestyle Study. Journal of the American Geriatrics Society, 59, 788-796.

Gennuso, K. P., Gangnon, R. E., Matthews, C. E., ThraenBorowski, K. M., \& Colbert, L. H. (2013). Sedentary behavior, physical activity, and markers of health in older adults. Medicine \& Science in Sports \& Exercise, 45, 1493-1500.

Gianoudis, J., Bailey, C. A., \& Daly, R. M. (2015). Associations between sedentary behaviour and body composition, muscle function and sarcopenia in community-dwelling older adults. Osteoporosis International, 26, 571-579.

Harris, T. J., Owen, C. G., Victor, C. R., Adams, R., Ekelund, U., \& Cook, D. G. (2009). A comparison of questionnaire, accelerometer, and pedometer: Measures in older people. Medicine \& Science in Sports \& Exercise, 41, 1392-1402.

Hart, T., Swartz, A., Cashin, S., \& Strath, S. (2011). How many days of monitoring predict physical activity and sedentary behavior in older adults? International Journal of Behavioral Nutrition and Physical Activity, 8, 62.

Harvey, J. A., Chastin, S. F. M., \& Skelton, D. A. (2013). Prevalence of sedentary behavior in older adults: A systematic review. International Journal of Environmental Research and Public Health, 10, 6645-6661.

Harvey, J. A., Chastin, S. F. M., \& Skelton, D. A. (2015). How sedentary are older people? A systematic review of the amount of sedentary behavior. Journal of Aging and Physical Activity, 23, 471-487.

Henson, J., Yates, T., Biddle, S. J. H., Edwardson, C. L., Khunti, K., Wilmot, E. G., ... Davies, M. J. (2013). Associations of objectively measured sedentary behaviour and physical activity with markers of cardiometabolic health. Diabetologia, 56, 1012-1020.

Hill, J., \& Wyatt, H. (2005). Role of physical activity in preventing and treating obesity. Journal of Applied Physiology, 99, 765-770. 
Inoue, S., Sugiyama, T., Takamiya, T., Oka, K., Owen, N., \& Shimomitsu, T. (2012). Television viewing time is associated with overweight/obesity among older adults, independent of meeting physical activity and health guidelines. Journal of Epidemiology, 22, 50-56.

Jefferis, B. J., Parsons, T. J., Sartini, C., Ash, S., Lennon, L. T., Wannamethee, S. G., ... Whincup, P. H. (2016). Does duration of physical activity bouts matter for adiposity and metabolic syndrome? A cross-sectional study of older British men. International Journal of Behavioral Nutrition and Physical Activity, 13, 36.

Ko, S. U., Stenholm, S., \& Ferrucci, L. (2010). Characteristic gait patterns in older adults with obesity - results from the Baltimore Longitudinal Study of Aging. Journal of Biomechanics, 43, 1104-1110.

Loprinzi, P. D., Crush, E., \& Joyner, C. (2017). Cardiovascular disease biomarkers on cognitive function in older adults: Joint effects of cardiovascular disease biomarkers and cognitive function on mortality risk. Preventive Medicine, 94, 27-30.

Loveloj, J., Champagne, C., de Jonge, L., Xie, H., \& Smith, S. (2008). Increased visceral fat and decreased energy expenditure during the menopausal transition. International Journal of Obesity, 32, 949-958.

Owen, N., Bauman, A., \& Brown, W. (2009). Too much sitting: A novel and important predictor of chronic disease risk? British Journal of Sports Medicine, 43, 80-83.

Park, K. S., Lee, D. H., Lee, J., Kim, Y. J., Jung, K. Y., Kim, K. M., ... Lim, S. (2016). Comparison between two methods of bioelectrical impedance analyses for accuracy in measuring abdominal visceral fat area. Journal of Diabetes and its Complications, 30, 343-349.

Pelclova, J., Fromel, K., Gaba, A., \& Mitas, J. (2012). Perceived neighborhood environment and physical activity in Central European older adults. Journal of Science and Medicine in Sport, 15(Suppl. 1), S268.

Pelclová, J., Gába, A., Přidalová, M., Engelová, L., Tlučáková, L., \& Zając-Gawlak, I. (2009). Vztah mezi doporučeními vztahujícími se k množství pohybové aktivity a vybranými ukazateli zdraví u žen navštěvujících univerzitu třetího věku [Relationship between physical activity recommendations and selected indicators of health in women attending the University of Third Age]. Tělesná kultura, 32(2), 64-78.

Pelclová, J., Gába, A., Tlučáková, L., \& Pośpiech, D. (2012). Association between physical activity (PA) guidelines and body composition variables in middle-aged and older women. Archives of Gerontology and Geriatrics, 55, e14-e20.

Penedo, F. J., Schneiderman, N., Dahn, J. R., \& Gonzalez, J. S. (2004). Physical activity interventions in the elderly: Cancer and comorbidity. Cancer Investigation, 22, 51-67.
Piché, M. È., Lapointe, A., Weisnagel, S. J., Corneau, L., Nadeau, A., Bergeron, J., \& Lemieux, S. (2008). Regional body fat distribution and metabolic profile in postmenopausal women. Metabolism: Clinical and Experimental, 57, 1101-1107.

Recio-Rodríguez, J. I., Sanchez-Aguadero, N., RodríguezSánchez, E., Martinez-Vizcaino, V., Martin-Cantera, C., Patino-Alonso, M. C., ... Garcia-Ortiz, L. (2017). Physical activity and adiposity among the older adults of the evident study. Journal of Aging and Physical Activity, 25, 254-260.

Sabia, S., Cogranne, P., Hees, V. T. Van, Bell, J. A., Elbaz, A., Kivimaki, M., \& Singh-Manoux, A. (2015). Physical activity and adiposity markers at older ages: Accelerometer vs questionnaire data. Journal of the American Medical Directors Association, 16, 438.e7-438.e13.

Shiroma, E. J., Freedson, P. S., Trost, S. G., \& Lee, I.-M. (2013). Patterns of accelerometer-assessed sedentary behavior in older women. Journal of the American Medical Association, 310, 2562-2563.

Strath, S. J., Holleman, R. G., Ronis, D. L., Swartz, A. M., \& Richardson, C. R. (2008). Objective physical activity accumulation in bouts and nonbouts and relation to markers of obesity in US adults. Preventing Chronic Disease Public Health Research, Practice and Policy, 5(4), 1-11.

Taylor, A. H., Cable, N. T., Faulkner, G., Hillsdon, M., Narici, M., \& Van der Bij, A. K. (2004). Physical activity and older adults: A review of health benefits and the effectiveness of interventions. Journal of Sports Sciences, 22, 703-725.

UK Department of Health. (2011). UK physical activity guidelines. Retrieved from https://www.gov.uk/government/ publications/uk-physical-activity-guidelines

World Health Organization. (2010). Global recommendations on physical activity for health. Geneva, Switzerland: Author.

World Health Organization. (2016). Monitoring health for the $S D G$ 's. Geneva, Switzerland: Author.

World Health Organization. (2017). Global recommendations on physical activity for health. Geneva, Switzerland: Author.

Yerrakalva, D., Cooper, A. J., Westgate, K., Khaw, K. T., Wareham, N. J., Brage, S., ... Winjdaele, K. (2017). The descriptive epidemiology of the diurnal profile of bouts and breaks in sedentary time in older English adults. International Journal of Epidemiology, 46, 1871-1881.

Zając-Gawlak, I., Pośpiech, D., Kroemeke, A., Mossakowska, M., Gába, A., Pelclová, J., ... Kłapcińska, B. (2016). Physical activity, body composition and general health status of physically active students of the University of the Third Age (U3A). Archives of Gerontology and Geriatrics, 64, 66-74. 